\title{
Supplementation, Optimal Status, and Analytical Determination of Vitamin D: Where are we Standing in 2012?
}

\author{
Jean-Claude Souberbielle ${ }^{1}$ and Etienne Cavalier ${ }^{2, *}$ \\ ${ }^{1}$ Service des Explorations Fonctionnelles Hôpital Necker-Enfants malades, Assistance Publique-Hôpitaux de Paris (AP-HP), Paris, \\ France; ${ }^{2}$ Department of Clinical Chemistry, University of Liège, CHU Sart-Tilman, Liège, Belgium
}

\begin{abstract}
There is a growing interest for vitamin D in the medical and scientific community as well as in the public medias as illustrated by a huge number of publications. Most experts claim that vitamin D deficiency/insufficiency is widespread with potential important public health consequences. It may seem surprising for many persons that a deficiency in a vitamin may be so frequent in countries where food is so diversified and easily available. In fact, vitamin D is not a vitamin stricto sensu as it is mainly synthesized in the skin under the action of UVB rays, while its food sources are scarce. Furthermore, UVB rays are absent during a marked part of the year at latitudes greater than $35-40^{\circ}$, while pollution and cloud cover reduce the number of UVB reaching the earth, and many factors such as age, skin pigmentation, covering clothes, sun creams reduce the capacity of the skin to synthesize vitamin D3. Vitamin D must be hydroxylated to form 1,25 dihydroxyvitamin $\mathrm{D}(1,25 \mathrm{OH} 2 \mathrm{D})$, the active metabolite. As $1,25 \mathrm{OH} 2 \mathrm{D}$ is released into the bloodstream and binds to a receptor present in several distant tissues, it may be considered as a hormone, vitamin $\mathrm{D}$ being thus a pre-prohormone. In the present article, we review briefly the metabolism and various effects of vitamin $\mathrm{D}$ as well as the vitamin $\mathrm{D}$ assays and vitamin $\mathrm{D}$ treatments. We define vitamin D deficiency/insufficiency considering separately the population and the patient level and propose our opinion about which patients may benefit from vitamin $\mathrm{D}$ testing.
\end{abstract}

Keywords: Vitamin D, 25-hydroxyvitamin D, Calcitriol, Parathyroid hormone, Immunoassay, Mass spectrometry, Reference values.

\section{METABOLISM AND EFFECTS OF VITAMIN D}

Vitamin D comprises a group of fat-soluble seco-steroids that play an essential role in calcium homeostasis and the development and maintenance of the skeleton. The two major forms of vitamin D are vitamin D3, also known as cholecalciferol, and vitamin D2, also named ergocalciferol. Vitamin D2 is found in plants, mainly yeast and fungi, whereas vitamin D3 is synthesised in the human skin from its precursor, 7-dehydrocholesterol, under the influence of ultraviolet B light (UVB). In addition, vitamin D3 is also contained in a few foods of animal origin. As vitamin D3 can be produced by exposure of the skin to sunlight, it is not a vitamin in the strict definition. The dietary sources of vitamin $\mathrm{D}$ are scarce, the only really significant ones being marine fatty fish (D3) although egg yolk (D3) and some mushrooms (D2) could be additional sources. One exception is the dried Shitake mushroom which contains significant quantities of vitamin D2. Some countries practice fortification of certain foods with vitamin D2 or D3, most often, milk, cereals, margarine and/or butter and infant formula. It is important to recognize that vitamin $\mathrm{D}$ is primarily made in the skin after exposure to the sun (D3) and less than $20 \%$ is derived from dietary sources. While the sufficient UVB is present throughout the year in the tropical zone, its is absent for a significant part of the year when we move away from the Equator (i.e. approximately 6 months in our cities, Paris and Liège). Whereas somebody with a fair skin exposing himself or herself to the sun in a bathing suit during 20-30 minutes around noon in a clear summer day can make up to $15,000 \mathrm{IU}$ vitamin D3 [1], living in a sunny area is not synonymous of having an optimal vitamin D status. Indeed, one needs to expose his or her skin to the sun to produce vitamin D3. It is of note that the cutaneous synthesis of vitamin D3 is less efficient in elderly compared to young people, and in Blacks compared to Caucasians, while it is decreased by the use of sunscreen, and absent in those wearing covering clothes. Furthermore, cloud cover

*Address correspondence to this author at the Department of Clinical Chemistry, University of Liège, CHU Sart-Tilman, 4000 Liège, Belgium; Tel: 324 3667692; G-Fax: 324 3667691;

E-mail: etienne.cavalier@chu.ulg.ac.be or pollution both decrease the amount of UVB reaching the earth, and thus the production of vitamin D3 by the skin.

Vitamin D, either D2 or D3, circulates in the bloodstream, bound to a specific protein, the vitamin D binding protein (DBP). To become fully active, vitamin $\mathrm{D}$ needs to be transformed twice. A first hydroxylation occurs in the liver to form 25-hydroxyvitamin D (25OHD). This liver hydroxylation is not tightly regulated and the more vitamin D is synthesized or ingested, the more 25OHD is produced by the liver. 25OHD circulates in the bloodstream bound to DBP, with a half-life of approximately 3 weeks. It may be hydroxylated in the kidney within the cells of the proximal tubule to form 1,25 dihydroxy vitamin $\mathrm{D}(1,25 \mathrm{OH} 2 \mathrm{D})$ also called calcitriol, which is the active vitamin $\mathrm{D}$ metabolite. This renal hydroxylation is very tightly regulated, stimulated by parathyroid hormone (PTH) and inhibited by fibroblast growth factor 23 (FGF23) and calcitriol itself. Calcitriol is released into the bloodstream and binds, in various distant tissues (i.e. intestine, bone, parathyroids...), to a cytosolic receptor, the VDR. The VDR associates with the retinoic acid receptor (RXR) and the trimeric complex (calcitriol-VDRRXR) binds to the DNA in special sites called "vitamin D responsive elements" (VDRE) to activate or inhibit the transcription of various genes. Calcitriol can thus be considered a true hormone. It is of interest that 25OHD can be inactivated in the kidney through a pathway involving a 24-hydroxylase whose expression is stimulated by FGF23 and calcitriol. The importance of this 24hydroxylase has been highlighted recently with the demonstration that inactivating mutations of the gene (CYP24A1) coding for this enzyme induce hypersensitivity to vitamin $\mathrm{D}$ with severe neonatal hypercalcemia [2].

The main classical effects of vitamin D through the endocrine action of calcitriol are to stimulate the absorption of calcium and phosphate by the gut, to regulate bone metabolism, and to exert a negative feed-back on PTH secretion. A severe deficiency in vitamin $\mathrm{D}$ may induce diseases characterized by bone mineralization defects, such as rickets in children and osteomalacia in adults [3]. Less severe deficiency may favour/worsen osteoporosis, especially on cortical bone. Supplementation with vitamin D (800 IU/day at least) with calcium has been shown to significantly reduce the relative risk of non vertebral fractures in 
subjects aged 60 years or older [4]. Correction of vitamin D deficiency/insufficiency is also a prerequisite before prescribing anti-osteoporotic drugs [5] and especially bisphosphonates [6].

Numerous tissues not involved in bone and/or calcium/ phosphorus metabolism are also able to express both the VDR and the enzymatic machinery that activates/inactivates vitamin D. 25OHD enters these tissues and is locally transformed into calcitriol that binds to the VDR expressed in the cell and exerts various (non "calcemic") genomic effects. This locally produced calcitriol is thought to stay within the producing tissue and thus does not participate in calcium/phosphorus metabolism. Its production does not seem to be regulated by calciotropic hormones (PTH, FGF23...) and depends probably on the 25OHD concentration in the extra-cellular fluid of these tissues. This is the basis for the (commonly called) "non-classical" effects of vitamin D that can be considered as "intracrine" by contrast with the endocrine abovementioned classical effects. It is of note that a huge number of genes contain VDRE and are thus probably responsive to vitamin D. Circulating calcitriol can also exert non genomic effects through the binding in some tissues to membrane proteins with subsequent modification of the intra-cellular calcium flux and stimulation of tyrosine-kinases.

The metabolism of vitamin D is summarized in Fig. (1).

Among the most frequently discussed non classical effects of vitamin $\mathrm{D}$ are those on:

- The muscle, with several studies showing that vitamin D supplemention (800 IU/day at least) with calcium significantly reduces the relative risk of falls in elderly patients [7], which may explain in part the reduction in the risk of non-vertebral fractures.

- The immune system. Briefly vitamin D stimulates innate immunity with potential protective effects against some infectious diseases [8], and inhibits some part of the adaptative immunity (especially shifting Th1 and Th17 lymphocytes towards a Th2 and Treg phenotype) with potential protective effects on some auto-immune diseases [9].

- The cardio-vascular system possibly via direct (cardiac and vascular cells express both the VDR and the 1-alpha hydroxylase) and indirect effects (calcitriol controls insulin secretion and sensitivity, inflammation, PTH, and renin, and thus blood pressure [10]).

- Some cancers, especially colorectal cancer [11]. See most other articles in this issue of the Journal.

- Adverse pregnancy outcomes such as preeclampsia and gestational diabetes $[12 ; 13]$. It is important to underline that vitamin D metabolism is greatly modified during pregnancy. In brief, while the 25OHD concentration of the pregnant women seems similar to what is found in the general population, the DBP and calcitriol levels both increase. Especially, the $1,25 \mathrm{OH} 2 \mathrm{D}$ level of pregnant women is $50-150 \%$ higher than in non pregnant women without any increase of serum calcium[14]. This calcitriol increase seems to be due to a secretion by the placenta in addition to the usual renal synthesis, and probably allows an increase in the intestinal absorption, and placental transport of calcium and phosphorus. A recent RCT comparing the effect of 400, 2000, and $4000 \mathrm{IU}$ vitamin D3/day in 350 pregnant women has shown that $1,25 \mathrm{OH} 2 \mathrm{D}$ concentrations of the participants were directly influenced by their circulating 25OHD levels throughout pregnancy, with maximal production of $1,25 \mathrm{OH} 2 \mathrm{D}$ in the 4000 IU group [15]. Serum 25OHD concentration of the foetus is dependent on the maternal level while 1,25OH2D is probably produced by the kidney of the foetus.

All the effects of vitamin D are probably partly influenced by the genetic environment. Indeed several single nucleotide polymorphisms of the genes coding for the DBP, the 1-alpha hydroxylase or the VDR exist with potential influence on the 25OHD and 1,25OH2D concentrations and their effects.

\section{DEFINITION OF OPTIMAL VITAMIN D STATUS}

This chapter aims to define vitamin D deficiency/insufficiency on the one hand, but also vitamin D excess on the other hand. First of all, it must be reminded that the measurement of $1,25 \mathrm{OH} 2 \mathrm{D}$, the most active vitamin D metabolite, is not indicated to evaluate vitamin $\mathrm{D}$ status. It must be limited to the diagnosis and management of rare disorders of phosphate and vitamin D metabolism, to the management of some patients with renal failure, and to the differential diagnosis of conditions presenting with hypercalcemia/hypercalciuria associated with low/low normal PTH levels. Second, it is a consensus, even among groups that released divergent recommendations on vitamin $\mathrm{D}[16 ; 17]$, that the measurement of $25 \mathrm{OHD}$ is the only measurement indicated to evaluate somebody's vitamin D status. What is not consensual however is the 25OHD cut-off value below which vitamin D status may be considered as insufficient. Indeed, contrary to most other biological parameters, 25OHD reference values should not be "population-based" (i.e. the range of values corresponding to what is found in $95 \%$ of an apparently healthy population) but should rather be "health-based". This means that defining vitamin D insufficiency corresponds to define the 25OHD level below which adverse outcomes may occur on the one hand, and/or above which beneficial effects of vitamin D may be observed. This supposes that RCTs demonstrating positive effects of vitamin D compared to placebo on clinical ("hard") outcomes are available, and that the 25 OHD concentrations in the "vitamin D groups" of theses RCTs have been evaluated. It must be underlined that, with the exception of the effect on the risk of falls, the many evidences concerning the various potential extra-skeletal effects of vitamin $D$, although plentiful, are mostly based on observational and mechanistic studies. Although numerous prospective studies have shown that subjects in the highest quantile of 25OHD concentrations (usually $>70-80 \mathrm{nmol} / \mathrm{L}$; multiply by 2.496 to convert $\mathrm{ng} / \mathrm{ml}$ to nmol/l) have a lower relative risk for many diseases than those in the lowest quantile (usually $<30-40 \mathrm{nmol} / \mathrm{L}$ ) [see for example 18 21], the observational nature of these studies does not allow to conclude a causal relationship between low vitamin D status and these diseases, and thus prevents defining clear clinical cut-off(s) to optimize these potential effects.

Like the expert panels from the Endocrine Society [16] or the Institute of Medicine (IOM) [17] who both recently released recommendations on the use of vitamin $\mathrm{D}$, we thus acknowledge that the only effects of vitamin D for which a "reasonably evidencebased" target value may be proposed are the effects on the musculoskeletal health and mineral metabolism (prevention of rickets/osteomalacia, elevated PTH levels, osteoporotic fractures, and falls in the elderly). While the recent report by the IOM [17] indicated that a $25 \mathrm{OHD}$ level of $50 \mathrm{nmol} / \mathrm{L}$ is largely sufficient and "covers the requirements of at least $97.5 \%$ of the population", we consider, as the Endocrine Society group and as many other vitamin D scientists [16; 22-30], that the optimal 25OHD level for musculoskeletal health should be $75 \mathrm{nmol} / \mathrm{L}$ and more in our (individual) patients. The discrepancy between these two conclusions may seem surprising as they are based on the analysis of virtually the same published data. It should be considered that the IOM cut-off is intended for public health recommendations while the Endocrine Society group targets its recommendations on patient care and considers that vitamin D deficiency (what should be avoided in any patient) corresponds to 25OHD levels <50 $\mathrm{nmol} / \mathrm{L}$, and insufficiency (what may be deleterious for a significant proportion of patients) to levels of 50 to $75 \mathrm{nmol} / \mathrm{L}$ [16]. To make things simple however, it is obvious that in clinical practice, we care for one patient at one time (not populations) and want that our 


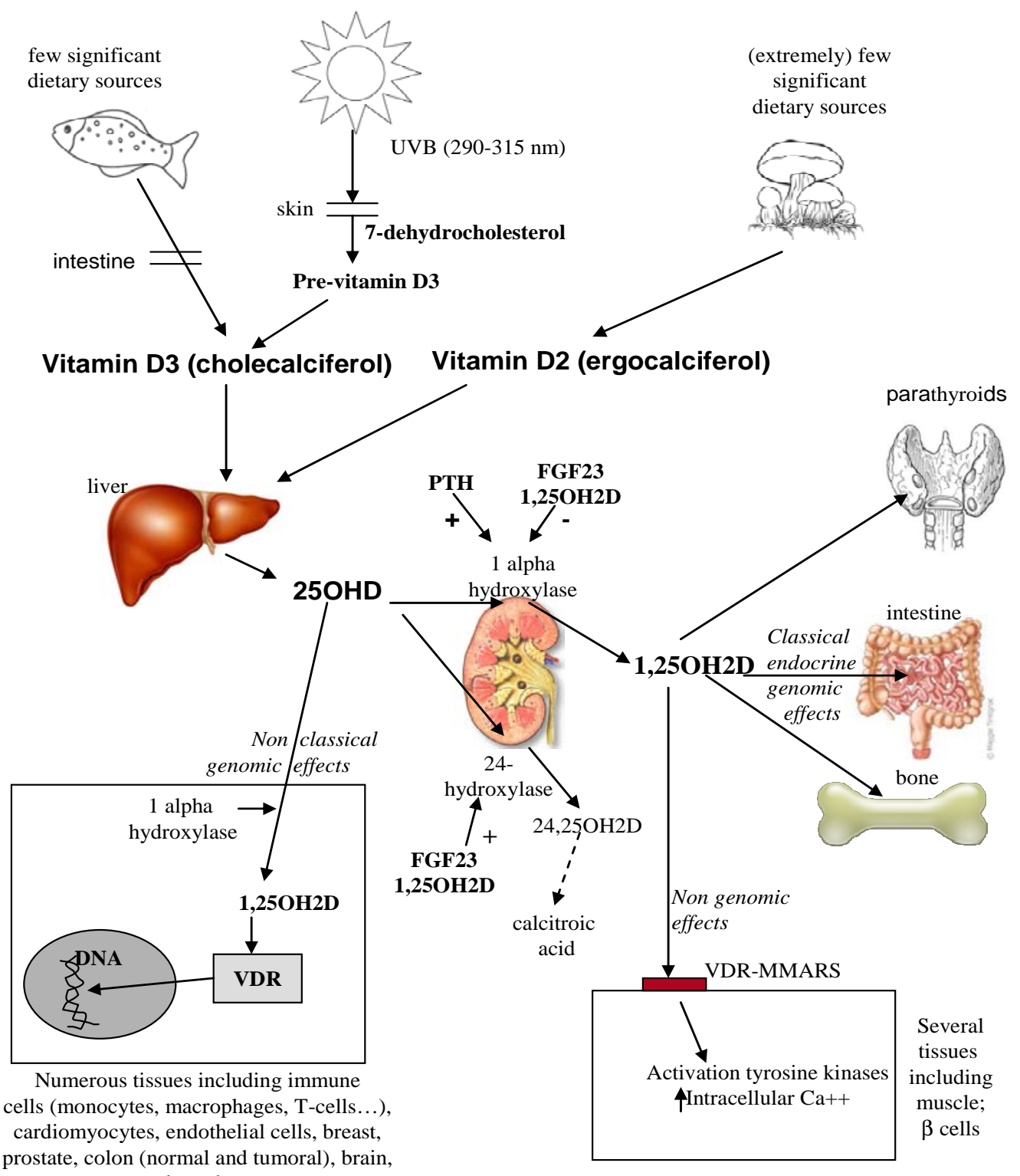

Fig. (1). Summary of the metabolism of vitamin D. Vitamin D2 and vitamin D3 are transported in the blood by the DBP and hydroxylated in the liver to form 25OHD, the concentration of which represents an individual's vitamin D status. Regulation of this hepatic hydroxylation is weak, and, the more vitamin D is ingested (D2 or D3) or synthesized in the skin (D3 only), the more 25OHD is produced. 25OHD is hydroxylated again to produce 1,25OH2D (also called calcitriol), the active vitamin D metabolite. This second hydroxylation can take place either in the proximal renal tubule, or in many other tissues. Renal hydroxylation - which is tightly regulated by calciotropic hormones, PTH and FGF23 - allows production of the 1,25OH2D "hormone" (i.e. which enters the blood and acts on distant target tissues binding to its receptor, the VDR). Peripheral hydroxylation seems independent of the calciotropic hormones but is dependent on the amount of circulating 25OHD. It forms 1,25OH2D which binds the VDR in the local tissue (where this 1,25OH2D has been formed), acts locally (in an intracrine manner), and does not participate to the calcium/phosphorus/bone metabolism. It is now demonstrated that in some tissues, circulating $1,25 \mathrm{OH} 2 \mathrm{D}$ is able to bind membrane proteins (probably variants of the VDR) with subsequent activation of different intra-cellular enzymes and/or modification of the intracellular calcium flux. Of note, an inactivating pathway through a 24-hydroxylase exists both in the kidney and peripheral tissues

patients achieve a "sufficient" level, not an "insufficient" one. Our target concentration is thus above $75 \mathrm{nmol} / \mathrm{L}$. Indeed, in the RCTs that shown positive effects of vitamin D on non-vertebral fractures [4] and falls [7], subjects in the "vitamin D groups" had generally 25OHD levels of more than $75 \mathrm{nmol} / \mathrm{L}$, whereas those in the "placebo groups" had levels mostly in the 30-60 $\mathrm{nmol} / \mathrm{L}$ range. Consistent with these RCTs, bone biopsy data showed that histomorphometric signs of bone mineralization defect are not detected in subjects with a serum 25OHD level of more than 75 $\mathrm{nmol} / \mathrm{L}$ while they are present, as defined by the most conservative threshold of the OV/BV ratio of $2 \%$, in approximately $20 \%$ of those with a 25OHD level between 50 and $75 \mathrm{nmol} / \mathrm{L}$ [31].
Furthermore, Japanese patients with a basal 25OHD concentration of up to $70 \mathrm{nmo} / \mathrm{L}$ decreased their PTH concentration when they were given vitamin D (without calcium) [32], while the relationship between serum 25OHD and PTH levels in various populations indicated in some studies (but not all), that the PTH concentration may increase when $25 \mathrm{OHD}$ is below $75-80 \mathrm{nmol} / \mathrm{L}$ [33]. Also, in one study (but not others), it was demonstrated that calcium absorption was improved in menopausal women when the 25OHD serum concentration increased to approximately $80 \mathrm{nmol} / \mathrm{L}$ [34]. Finally, recent data indicate that a 25OHD serum level of 82 $\mathrm{nmol} / \mathrm{L}$ at least is required to optimize the anti-fracture efficacy of bisphosphonates [6]. 
Considering this threshold of $75 \mathrm{nmol} / \mathrm{L}$, but even with the more conservative IOM cut-off of $50 \mathrm{nmol} / \mathrm{L}$, insufficient vitamin D status is highly frequent. Indeed, approximately $80 \%$ and $50 \%$ of the general European population have a $25 \mathrm{OHD}$ level below 75 $\mathrm{nmol} / \mathrm{L}$, and $50 \mathrm{nmol} / \mathrm{L}$ respectively, and some groups such as institutionalized persons, dark-skinned individuals or immigrants, are even very frequently severely deficient $(25 \mathrm{OHD}<25 \mathrm{nmol} / \mathrm{L})$ as reviewed recently [35]. Then, an obvious question arises: "How could it be possible to find so frequently a deficiency in a vitamin in countries where food is largely available and varied?" The obvious answer is, as mentioned above, that vitamin $\mathrm{D}$ is not a true vitamin as its main source is not nutritional but through the synthesis by the skin.

Having proposed a threshold for vitamin D insufficiency, we must now propose an upper optimal level. In our laboratories, we use a value of $150 \mathrm{nmo} / \mathrm{L}$ which is chosen arbitrarily as a level that is much lower compared to the potential toxicity zone (25OHD>375 nmol/L [36]). Furthermore, to date no data exist on long-term tolerance (several years) of 25OHD serum levels of 200 $\mathrm{nmol} / \mathrm{L}$ and more, and similarly there are no RCT showing that a 25OHD level of $150-350 \mathrm{nmol} / \mathrm{L}$ has any clinical advantage compared to levels of $75-150 \mathrm{nmol} / \mathrm{L}$. We can also take into consideration that some observational studies (very few in fact) have suggested a U-shaped relationship between 25OHD serum concentrations and the relative risk for prostate cancer [37], and other rare cancers [38] (higher risk for low 25OHD concentration but also for high concentrations) which urge caution while awaiting more definitive data. Thus our proposed 25OHD reference range that we call "desirable" or "recommended" values rather than "normal" values is currently $75-150 \mathrm{nmol} / \mathrm{L}$. While taking due note of the abundant scientific literature, we do not rule out the possibility that these "desirable" values may evolve as new data are published. It can be noted that the upper levels of this target range is very close to the $25 \mathrm{OHD}$ concentrations recently found in traditionally living population in East Africa, the Massai, and the Hadzabe, who have lifelong, year-round exposure to tropical sunlight [39].

\section{VITAMIN D ASSAYS}

25OHD assays should be considered as routine assays since they allow evaluation of vitamin D status. They are still not easy to develop [40] and those available do not all meet the quality criteria that should be required for a routine clinical measurement. The main difficulties arise from the fact that 25OHD is a highly hydrophobic molecule, and there are two forms to be assayed, $25 \mathrm{OHD} 2$, and 25OHD3. The presence of significant amounts of a 25OHD C3-epimer in some patients, especially in newborns, renders the problem even more complex as it is still unclear whether this variant should be measured or not [41]. 25OHD assay techniques can be split into two large families, immunoassays, the most commonly used currently, and separation methods such as high performance liquid chromatography (HPLC) or tandem mass spectrometry (MS-MS). Both have their own advantages and limitations. Immunoassays are relatively easy to perform but they may be limited by cross-reactivity of the antibodies which may induce non equimolecular recognition of the various vitamin D compounds such as 25OHD2 and 25OHD3. They produce global results (i.e. the sum of all the measured metabolites). Separative methods need very experienced technicians, and necessitate highly expensive machines. However, once the machine is present in a laboratory and has been paid, the cost of a measurement in terms of reagents is much less than with the immunoassays. These methods provide separate concentrations for the different measured compounds that have to be subsequently summed.

In practice, there is no obvious argument for preferential use of a particular type of sample (serum or plasma). Serum seems to be used most often although it is suggested to avoid gel tubes [42].
25OHD is extremely stable in the serum, probably as a result of its binding with the DBP, making any special precaution for sample storage unnecessary. It is important that the laboratory participates in an external quality control (as for any other biological parameter). However, the hydrophobic nature of 25OHD is likely to induce very significant matrix effects which means that external quality control programs that offer "spiked" samples instead of real serum samples do not allow inter-method comparison [43]. An external quality control that uses "true" serum samples and is now accepted by many laboratories worldwide is the UK-based DEQAS (www.deqas.com). It is important to choose an assay technique that measures both 25OHD2 and 25OHD3 equally. This is particularly important in countries where vitamin D 2 is available as a supplement or in fortified food. A technique assaying only 25OHD3 inevitably underestimates the (total) 25OHD concentration so that a patient taking vitamin D2 supplements could easily be considered as vitamin D deficient while he is not [44]. If a method such as MS/MS, measuring separately $250 H D 2$ and 25OHD3, is used, it is imperative that the sum of the two forms appears as the main results on the result sheet [45]. This is the only important information for the clinician.

It must be understood that the threshold(s) defining vitamin $\mathrm{D}$ deficiency ( 50 or $75 \mathrm{nmol} / \mathrm{L}$ ) is (are) based mostly on studies that used the same 25OHD assay, i.e. the "historic" DiaSorin radioimmunoassay (RIA) [46], but these thresholds are currently used whatever assay method is used. However, with the increase of laboratories that measure $25 \mathrm{OHD}$, and with the availability of fully automated immunoassays, the DiaSorin RIA is now used by only a limited number of laboratories. It is thus important to question whether the different available assays produce similar results, in other words, whether they are standardized. Indeed, in case of poor standardization, strict application of a cut-off value would lead to different diagnoses and therapeutic actions. To standardize different assay methods for a given analyte, one needs a reference preparation and a reference method with a reference measurement procedure. Although not yet official (February 2012), it is probably a matter of months. Indeed, candidate reference measurement procedures for serum 25OHD3 and 25OHD2 by using isotope dilution liquid chromatography-tandem mass spectrometry (LCMS/MS) and an accepted reference material (NIST) have been achieved and published recently [47]. It must be understood that this reference measurement procedure was developed to enable unequivocal validation and calibration of immunoassays and other methods and is not a routine practice. Its goal is to harmonize the results from the different methods used worldwide. When looking at the results of the International 25OHD quality control DEQAS, or at the results of recent studies that compared the most commonly used 25OHD assays [48; 49] two different conclusions may be reached. The optimistic conclusion is that the situation is not so bad as, according to the DEQAS results, the mean difference between the two most discrepant assays is $25-35 \%$ for concentrations in the $20-80 \mathrm{nmol} / \mathrm{L}$ range. This is very comparable to and even better than what is found when different assays for other commonly measured steroids such as testosterone [50] or progesterone [51] are compared. A great difference however between 25OHD assays and testosterone assays is the fact that testosterone reference values are specific to each kit, reducing thus greatly the impact of the intermethod variability, whereas a $250 \mathrm{OH}$ concentration is interpreted (low, normal, or high) by comparison with the same cut-off values whatever the 250HD assay is. Thus, the obvious and more pessimistic conclusion is that even a moderate difference of, say $10-15 \%$, between the results of two 25OHD kits may have clinical/therapeutic consequences, as a significant proportion of patients may be classified differently ("insufficient" or "normal") by the two kits by comparison to the clinical cut-off. This has been reported and discussed in several publications during the recent years [52-54]. It is likely that in the near future, these discrepancies 
will be reduced due to the harmonization of the various commercial assays by comparison with the reference method procedure.

\section{IN WHICH PATIENTS SHOULD VITAMIN D TESTING BE PERFORMED?}

The considerable amount of recently published data on the proven or potential effects of vitamin $\mathrm{D}$ has raised much interest in the medical community. One of the consequences has been a great increase in the prescription of vitamin D measurements in clinical practice. In France, for example, the prescription of 25OHD testing has been multiplied by almost 3 between 2008 and 2010. As this measurement is reimbursed by the public health insurance (currently 17.55 Euros in France), it seems obvious to evaluate whether these prescriptions are justified or not. It must be emphasized that definitive recommendations on testing or not testing vitamin $\mathrm{D}$ in clinical practice must only be released by official Clinical Societies such as the Endocrine Society, and, thus, the following suggestions should only be considered as reflecting our current opinion (which may change with the publication of new data) based on our own analysis of the literature, and our routine clinical practice. We must mention a quite recent article co-signed by both of us [30], which reported the opinion of a panel of 25 experts from various disciplines. In this paper, most authors recommended to measure the 25OHD serum level in clinical practice in a myriad of medical conditions including pregnant women, patients with cancers, auto-immune diseases, cardiovascular diseases, hypertension and diabetes. Two years after the publication of this article, we (JCS, EC) would not give the same advice concerning the need to test vitamin $\mathrm{D}$ in these patients. Indeed, time has passed, and it has become clear that vitamin $\mathrm{D}$ doses of $2000 \mathrm{IU} /$ day (and even more) are perfectly safe even if administered to subjects who have a spontaneous 25OHD level in the highest quartile of the general population (usually in the 70-90 $\mathrm{nmol} / \mathrm{L}$ range), assuming they have no granulomatous disease (sarcoidosis, tuberculosis...) or hypersensitivity to vitamin D due to a genetic defect [2]. We thus do not recommend anymore to evaluate vitamin D status systematically in patients with (or at risk of) cardiovascular diseases, auto-immune diseases, cancers, infections, as well as in pregnant or lactating women. However, this opinion may change again according to newly published data (for example if one of the ongoing RCTs demonstrates that vitamin D supplementation improves one or several clinical extra-skelettal outcomes when a given 25OHD level is achieved). In the interval, we rather propose to supplement these patients with vitamin D without prior testing (although we don't consider that measuring $25 \mathrm{OHD}$ in some cancer, multiple sclerosis, HIV, or hypertensive patients is a "crime"). We are aware however that in our countries (France and Belgium) at least, many doctors are still reluctant to prescribe vitamin D supplementation without knowing the vitamin D status of their patients, and, similarly, some patients would not agree to take a vitamin D treatment if a vitamin D deficiency/ insufficiency has not been evidenced by a low 25OHD level.

In our opinion, vitamin $\mathrm{D}$ testing is still highly legitimate in several groups of patients for whom a "reasonably" evidence-based target concentration is available. As indicated above, our target concentration for musculoskeletal health and mineral metabolism is above $75 \mathrm{nmol} / \mathrm{L}$. Let us also underline that, due to the measurement uncertainty of 25OHD measurements (which is comparable to what is reported for the measurement of other steroid hormones), a value of $75 \mathrm{nmol} / \mathrm{L}$ in an individual patient means that the true value is (grossly) above $60 \mathrm{nmol} / \mathrm{L}$, and somewhere between 60 and $90 \mathrm{nmol} / \mathrm{L}$ [55].

So, among the patients in whom we propose to measure 25OHD to optimize bone/mineral health, we include:

Patients with rickets/osteomalacia.

Patients with osteoporosis (with and without fracture).
Patients at risk of osteoporosis/bone loss because they receive specific treatments such as glucocorticoids chronically at a dose of $7 \mathrm{mg}$ prednisone or more for any cause (see a recent review in [56]), analogs of GnRH for prostate cancer, or anti-aromatase therapy for breast cancer.

Patients at risk of osteoporosis/bone loss because they have a malabsorption syndrome (celiac disease, inflammatory bowel disease, cystic fibrosis, Crohn's disease...).

Patient who had bariatric Surgery, specially gastric bypass. Obese patients are usually vitamin D deficient but are not osteoporotic. However, after gastric bypass they have an accelerated bone loss. These patients cumulate two reasons for being vitamin $\mathrm{D}$ deficient: 1) even if they have lost $50 \mathrm{~kg}$ or more, they are usually still obese and trap vitamin $\mathrm{D}$ in their fat mass, and 2) they have a malabsorption due to the surgical procedure.

Patients with chronic kidney disease (CKD) stage 3-5D and kidney transplant recipients. Measuring 25OHD in CKD patients and treating vitamin $\mathrm{D}$ deficiency/insufficiency as in the general population is a recommendation of the KDIGO guidelines [57]. This recommendation is in fact only a suggestion which is graded 2C. Secondary hyperparathyroidism is a hallmark of CKD, with several deleterious consequences. It must be underlined that until recently, nephrologists used to treat their patients only with active vitamin D (analogs of calcitriol), not "natural" vitamin D, to control PTH secretion. Recent studies have shown that supplementation with cholecalciferol or ergocalciferol was able to decrease modestly but significantly PTH levels not only in non-dialyzed, but also in dialyzed and in transplant patients [58-61]. Furthermore, several prospective observational and non randomized interventional studies have linked vitamin D deficiency to increased mortality in CKD [62], accelerated GFR loss [63], and albuminuria [64]. This has made things to change, and supplementation with vitamin $\mathrm{D}$ is an increasing practice in CKD patients.

Patients with primary hyperparathyroidism (PHPT). These patients are often vitamin D deficient and osteoporotic, but they are also hypercalcemic. Treating hypercalcemic patients with a molecule that increases calcium absorption, and which may, when given at extremely large doses, cause hypercalcemia, hypercalciuria, and extra-skeletal calcifications was regarded with suspicion by most physicians. It was shown in 2005 that the administration of large doses of cholecalciferol to PHPT patients with a serum calcium level $<3 \mathrm{mmol} / \mathrm{L}$ did not increase serum calcium or phosphate, but decreased PTH significantly [65]. This was followed by similar published results (reviewed in [66]) so that the expert panel for the diagnosis/management of asymptomatic PHPT recommended to treat with vitamin D any PHPT patient with a $250 \mathrm{OHD}<50 \mathrm{nmol} / \mathrm{L}$ [67]. It is also recommended to supplement all PHPT patients with vitamin D (and calcium) once they have been surgically treated. This will allow an increase in bone mineral density and prevent symptomatic hypocalcemia due to "hungry bone syndrome". In our experience, 25OHD levels $>75 \mathrm{nmol} / \mathrm{L}$ (and sometimes more) are to be targeted after parathyroidectomy.

Patients with granulomatous disorders such as sarcoidosis or tuberculosis. In these patients it is prudent to target a 25OHD concentration around $50 \mathrm{nmol} / \mathrm{L}$ to avoid both hypercalcemia/ hypercalciuria due to uncontrolled synthesis of calcitriol on the one side, but also severe vitamin D deficiency which is frequent in these patients because of the fear of inducing hypercalcemia on the other side.

25OHD should also be measured in patients in whom symptoms compatible with a severe vitamin deficiency (such as 
those with diffuse pain or elderly subjects who frequently fall), or with a vitamin $\mathrm{D}$ intoxication (such as those with extraskeletal calcifications, nephrocalcinosis or recurrent renal stones) are present and persist without a clear explanation. Patients having a disease, such as hepatic failure, or receiving treatments that may modify vitamin D metabolism such as some anti-convulsants or ketokonazole can be included in this category. In these patients there is no special 25OHD range to recommend although it is logical to consider $50-150 \mathrm{nmol} / \mathrm{L}$.

More generally, 25OHD testing is recommended in any patient in whom an exploration of calcium/phosphate metabolism which includes a measurement of serum PTH is prescribed whatever the reason is (osteoporotic patients to exclude a secondary cause of low bone mass and/or fractures, patients with kidney stones, chondrocalcinosis, and in case of persistence without explanation of symptoms of both hyper- or hypocalcemia). In such cases, knowing the 25OHD level is specially important when a high PTH concentration is detected in a patient who has otherwise a normal serum calcium and phosphate level. Indeed, this may help to differentiate between a secondary hyperparathyroidism, for which vitamin D insufficiency/deficiency is one of the most common causes along with renal failure, and a so-called "normocalcemic" PHPT which is now recognized as a quite frequent entity, probably necessitating the same treatment as hypercalcemic PHPT when osteoporosis, kidney stones or renal failure is present [68].

\section{TREATMENT/SUPPLEMENTATION WITH VITAMIN D}

Here, we can separate recommendations for the general population, and recommendations for individual patients distinguishing those in whom we measure $25 \mathrm{OHD}$, and the other patients.

Since insufficient vitamin D status is so common, since treatment is inexpensive and has a large safety margin (even the IOM considers doses up to 4,000 IU/day as safe in adults [17]), and since we already have much data suggesting that in addition to its classic proven effects on bone and mineral metabolism, vitamin D may potentially be helpful for the prevention/management of colorectal cancer, some infectious diseases, cardiovascular diseases, and some auto-immune diseases, perhaps should it be prescribed to everyone (without prior testing)? It is not up to us to give advices for the general population, but rather to the health authorities to implement - if they become convinced that the benefit-risk/cost ratio may be favourable - a prudent supplementation policy at national or regional level with the objective to increase the 25OHD levels so that most persons (95\%?) have $50 \mathrm{nmol} / \mathrm{L}$ or more. This would mean shifting the mean $25 \mathrm{OHD}$ level of the population of most European countries from approximately $50 \mathrm{nmol} / \mathrm{L}$ to approximately $75 \mathrm{nmol} / \mathrm{L}$. Assuming this goal, intake of $600 \mathrm{UI} /$ day as proposed by the IOM group for adults up to 70 years is probably insufficient as we know that, according to a rule of thumb, 1000 IU/day vitamin $\mathrm{D}$ will increase the $25 \mathrm{OHD}$ serum concentration by a mean 15 to $25 \mathrm{nmol} / \mathrm{L}$, but with a huge inter-individual variability [69]. So, intake of $1000 \mathrm{UI} /$ day is probably a better choice as suggested by a recent systematic review and meta-regression analysis of the vitamin D intake-serum 25OHD relationship [70]. We must however acknowledge that this is far from clear and there is a need for further studies. Indeed, in a more recently published RCT [71], a dose of 800 IU vitamin D3/day given for one year to healthy postmenopausal white women allowed to reach a mean $25 \mathrm{OHD}$ level of approximately $75 \mathrm{nmol} / \mathrm{L}$ and a level above 50 $\mathrm{nmol} / \mathrm{L}$ in almost all participants, while this was only achieved with $1600 \mathrm{IU} /$ day, and $2000 \mathrm{IU} /$ day in two other very recent trials respectively $[72 ; 73]$.

In patients in whom 25OHD testing is done, treatment will depend on the results of the measured 25OHD concentration with the aim to reach and maintain a serum level within the 75-150
nmol/L range. One can thus consider two phases, the first one aiming to raise the $25 \mathrm{OHD}$ level above $75 \mathrm{nmol} / \mathrm{L}$ ("correction" phase), and the second one aiming to maintain the 25OHD level $>75 \mathrm{nmol} / \mathrm{L}$ ("maintaining" phase). We know that the 25OHD concentration reached after taking one specific dose of vitamin D varies greatly from one patient to another. Two very important determinants of the increase in serum 250HD when a subject is given a specific dose of vitamin $\mathrm{D}$ are the initial 25OHD concentration and the patient's weight. A Dutch group has established an equation based on these two parameters that calculates the cumulative dose to be given in weekly doses of $25,000 \mathrm{IU}$ to achieve an average concentration of $75 \mathrm{nmol} / \mathrm{L}$ ten days after the last 25,000 IU dose [74]: $(\mathrm{kg})]$

Dose $(\mathrm{IU})=40[75-$ serum $25 \mathrm{HOHD}(\mathrm{nmol} / \mathrm{L})] \mathrm{x}$ [body weight

Thus, if we consider a $70 \mathrm{~kg}$ patient with a 25OHD level of 25 $\mathrm{nmol} / \mathrm{L}$, the dose calculated will be $140,000 \mathrm{IU}$, which, in practice, is $25,000 \mathrm{IU}$ every week over six weeks $(150,000 \mathrm{IU}$ in total). We should point out that the value of $75 \mathrm{nmol} / \mathrm{L}$ in this study was an average target, and that in practice around only half of the patients treated achieve a concentration $>75 \mathrm{nmol} / \mathrm{L}$. This study at least has the merit of opening a path for the determination of the "correction" dose. It is of note that several propositions of "correction" protocols using higher doses have been proposed by different experts (see for example $[22 ; 75]$ ) and can be adapted according to the vitamin D forms available in a given country. Once the "correction" phase is completed, a maintaining phase using the doses suggested by the Endocrine Society group as being the mean daily requirement that can be prescribed (for example 1500-2000 IU/day for adults -see Table 3 in [16]). Based upon the known variability in 25OHD response, it is advisable in these patients to repeat 25OHD measurement after 4-6 months of vitamin D supplementation at the "maintaining" dose and adapt the posology.

For other patients in whom 25OHD is not measured, we may consider two different propositions. The first one is to do for these patients as it is recommended for the general population [17]. The second one is to consider that, despite a lack of RCT with "hard" end-points, the many observational and experimental data linking vitamin $\mathrm{D}$ deficiency to an increased risk of several chronic disease, as well as the increasing number of RCTs showing better outcomes on intermediary parameters may encourage doctors to prescribe higher dosages. For those, like us, who prefer this second proposition, the above-mentioned doses suggested by the Endocrine Society group are encouraged without prior testing and, thus, without a "correction" phase, until the results of adequately powered RCTs are available. It is probable that, with these doses, and due to the important inter-individual variability in the 25OHD response to a given vitamin $\mathrm{D}$ dose, not everybody will have a $25 \mathrm{OHD}$ level above $75 \mathrm{nmol} / \mathrm{L}$, but a level of more than $50 \mathrm{nmol} / \mathrm{L}$ can be expected in most patients.

It must be underlined that due to the great disparity of vitamin D supplements that are available from one country to another, it is impossible to propose universal supplementation protocols. Indeed, in some countries only supplements providing daily doses of either vitamin D2 or vitamin D3 are available, while in other countries it is possible also to prescribe large doses of either compounds for intermittent administration. It is possible however to highlight several points for the clinical practice. A first question is whether daily dosages (which may seem more physiologic) or intermittent dosages (in order to favour observance/adherence) should be preferred when both are available. There is no obvious answer to this question but we think that, after having explained why vitamin $\mathrm{D}$ supplementation is important for the patient, the doctor may let the patient choose. If intermittent dosages are chosen (most frequently in our practice), doses, and interval between doses should not be too large. Indeed, daily doses and the same 
cumulative doses administered weekly or monthly (i.e. 1,500 IU daily, 10500 IU weekly, or 45,000 IU monthly) induce the same increase in the 25OHD concentration [76], while this is less obvious for larger intervals. Furthermore, in a recent 3-year RCT of 500,000 IU vitamin D3 versus placebo administered once a year to elderly women, more fractures and falls were recorded in the vitamin D group than in the placebo group [77]. Interestingly, this excess in the number of falls and fractures was only observed during the 3 months following each yearly administration of this large dose of vitamin D. A second question is whether vitamin D2 and vitamin D3 are equivalent. To answer to this question one has to differentiate the daily and the intermittent treatment. Indeed, it is now quite clear that when given intermittently, vitamin D2 is less potent than vitamin D3 to sustain the 25OHD level in a desirable range $[78 ; 79]$. However, when given daily, D2 and D3 seem to maintain the 25OHD similarly [80] although this is discussed [81].

\section{CONCLUSION}

Knowledge on each aspects of the vitamin D field have increased these last years.

This has led to question previously well-established thoughts. For instance, we know now for sure that the vitamin D status of a patient should not be based on the determination of $1,25 \mathrm{OH}_{2} \mathrm{OHD}$ (the most active metabolite), but rather on 25OHD. We also know that 25OHD reference range should not be based on a "reference population" but on clinical data. There is now a large consensus to acknowledge that insufficient vitamin D status is highly frequent in the general population, and that vitamin D supplementation to reach serum levels of $75 \mathrm{nmol} / 1$ is mandatory for a good bonemineralization, to reduce fracture and falls in the elderly. However, the target levels for other outcomes (hypertension, cardiovascular diseases, infections, auto-immune diseases, diabetes,...) are currently unknown and will probably be found according to new or ongoing randomized controlled studies with very well defined hard endpoints. Of note is that these targets will certainly vary according to the expected outcome. At that time, an important work on vitamin D assays standardization should have been done in order to avoid misinterpretation of the results. Finally, in medicine, the truth of today is not necessarily the truth of tomorrow, and new clinical and analytical data will probably change our perception in the next years.

\section{CONFLICT OF INTEREST}

The author(s) confirm that this article content has no conflict of interest.

\section{ACKNOWLEDGEMENTS}

Declared none.

\section{REFERENCES}

[1] Holick, M.F.; Chen, T.C.; Lu, Z.; Sauter, E. J. Vitamin and skin physiology: a delightful story. Bone Miner. Res., 2007, 2(suppl 2): V28-V33.

[2] Schlingmann, K.P.; Kaufmann, M.; Weber, S.; Irwin, A.; Goos, C.; John, U.; Misselwitz, J.; Klaus, G.; Kuwertz-Bröking, E.; Fehrenbach, H.; Wingen, A.; Güran, T.; Hoenderop, J.; Bindels, R.; Prosser, D.; Jones, G.; Konrad, M. Mutations in CYP24A1 and idiopathic infantile hypercalcemia. N. Engl. J. Med., 2011, 365, 410-421.

[3] Holick, M. Resurrection of vitamin D deficiency and rickets. $J$. Clin. Invest., 2006, 116, 2062-2072.

[4] Bischoff-Ferrari, H.; Willett, W.; Wong, J.; Stuck, A.; Staehelin, H.; Orav, J.; Thoma, A.; Kiel, D.; Henschkowski, J. Prevention of nonvertebral fractures with oral vitamin D and dose dependency. Arch. Int. Med., 2009, 169, 551-561.

[5] Adami, S.; Giannini, S.; Bianchi, G.; Sinigalia, L. Di.; Munno, O.; Fiore, C.E.; Minisola, S.; Rossini, M. Vitamin D status and response to treatment in post-menopausal osteoporosis. Osteoporos. Int., 2009, 20, 239-244.
[6] Carmel, E.S.; Shieh, A.; Bang, H.; Bockman, R.S. The 25(OH)D level needed to maintain a favourable bisphosphonate response is $>33 \mathrm{ng} / \mathrm{mL}$. Osteoporos. Int., 2012, Jan 12 [Epub ahead of print].

[7] Bischoff-Ferrari, H.; Dawson-Hughes, B.; Staehelin, H.B.; Orav, J.; Stuck, A.; Theiler, R.; Wong, J.; Egli, A.; Kiel, D.; Henschkowski, J. Fall prevention with supplemental and active forms of vitamin D: a meta-analysis of randomised controlled trials. BMJ, 2009, 339, b3692.

[8] Hewison, M. Antibacterial effects of vitamin D. Nat. Rev. Endocrinol., 2011, 7, 337-345.

[9] Boonstra, A.; Barrat, F.; Crain, C.; Heath, V.; Savelkoul, H.; O'Garra, A. 1,25-dihydroxyvitamin D3 has a direct effect on naïve CD4+T cells to enhance the development of Th2 cells. J. Immunol., 2001, 167, 4974-4980.

[10] Pilz, S.; Tomaschitz, A.; Ritz, E. Vitamin D status and arterial hypertension: a systematic review. Nat. Rev. Cardiol., 2009, 6, 621-630.

[11] Ma, Y.; Zhang, P.; Wang, F.; Yang, J.; Liu, Z.; Qin, H. Association between vitamin $\mathrm{D}$ and risk of colorectal cancer: a systematic review of prospective studies. J. Clin. Oncol., 2011, 29, 3775-3782.

[12] Bodnar, L.; Catov, J.; Simhan, H.; Holick, M.; Powers, R.; Roberts, J. Maternal vitamin D deficiency increases the risk of preeclampsia. J. Clin. Endocrinol. Metab., 2007, 92, 3517-3522.

[13] Zhang, C.; Qiu, C.; Hu, F.; David, R.; van Dam, R.; Bralley, A.; Williams, M. Maternal plasma 25-hydroxyvitamin D concentrations and the risk for gestational diabetes mellitus. PloS ONE, 2008, 3 , e3753.

[14] Brannon, P.; Picciano, M.F. Vitamin D in pregnancy and lactation in humans. Annu. Rev. Nutr., 2011, 31, 89-115.

[15] Hollis, B.W.; Johnson, D.; Hulsey, T.C.; Ebeling, M.; Wagner, C. Vitamin D supplementation during pregnancy: double blind randomized clinical trial of safety and effectiveness. J. Bone Miner. Res., 2011, 26, 2341-2357

[16] Holick, M.; Binkley, N.; Bischoff-Ferrari, H.; Gordon, C.; Hanley, D.; Heaney, R.; Murad, H.; Weaver, C. Evaluation, treatment and prevention of vitamin D deficiency: an Endocrine Society clinical practice guideline. J. Clin. Endocrinol. Metab., 2011, 96, 19111930.

[17] Ross, C.; Manson, J.E.; Abrams, S.; Aloia, J.; Brannon, P.; Clinton, S.; Durazo-Arvizu, R.; Gallagher, J.C.; Gallo, R.; Jone, G.; Kovacs, C.; Mayne, S.; Rosen, C.; Shapes, S. The 2011 report on dietary reference intakes for calcium and vitamin D from the Institute of Medicine: what clinicians need to know. J. Clin. Endocrinol. Metab., 2011; 96, 53-58.

[18] Munger, K.; Levin, L.; Hollis, B.; Howard, N.; Ascherio, A. Serum 25-hydroxyvitamin D levels and risk of multiple sclerosis. JAMA, 2006, 296, 2832-2838.

[19] Giovanucci, E. Epidemiological evidence for vitamin D and colorectal cancer. J. Bone Miner. Res., 2007, 22, V81-V85.

[20] Engel, P.; Fagherazzi, G.; Boutten, A.; Dupré, T.; Mesrine, S.; Boutron-Ruault, M.C.; Clavel-Chapelon, F. Serum 25(OH) vitamin $\mathrm{D}$ and risk of breast cancer: a nested case-control study from the French E3N cohort. Cancer Epidemiol. Biomarkers Prev., 2010, 19, 2341-2350.

[21] Leu, M.; Giovannucci, E. Vitamin D: epidemiology of cardiovascular risks and events. Best Pract. Res. Cl. En., 2011, 25, 633646.

[22] Adams, J.; Hewison, M. Update in vitamin D. J. Clin. Endocrinol. Metab., 2010, 95, 471-478.

[23] Norman, A. Vitamin D nutrition is at a crossroads. Public Health Nutrition, 2011, 14, 750-751.

[24] Dawson-Hughes, B.; Mithal, A.; Bonjour, J.P.; Boonen, S.; Burckardt, P.; Fuleihan, G.E.H.; Josse, R.G.; Lips, P.; MoralesTorres, J.; Yoshimura, N. IOF position statements: vitamin D recommendations for older adults. Osteoporos. Int., 2010, 21, 1151-1154.

[25] Perez-Lopez, F.; Brincat, M.; Erel, T.; Erel, T.; Tremollieres, F.; Gambacciani, M.; Lambrinoudaki, I.; Moen, M.; SchenckGustafsson, K.; Vujovic, S.; Rozenberg, S.; Rees, M. EMAS position statement: vitamin D and postmenopausal health. Maturitas, 2012, 71, 194-198.

[26] Vieth, R. Why the optimal requirement for vitamin D3 is probably much higher than what is officially recommended for adults. $J$. Steroid Biochem. Mol. Biol., 2004, 89, 575-579. 
[27] Bischoff-Ferrari, H.; Giovanucci, E.; Willett, W.; Dietrich, T.; Dawson-Hughes, B. Estimation of optimal serum concentrations of 25-hydroxyvitamin D for multiple outcomes. Am. J. Clin. Nutr., 2006, 84, 18-28.

[28] Dawson-Hughes, B.; Heaney, R.; Holick, M.; Lips, P.; Meunier, P.; Vieth, R. Estimates of optimal vitamin D status. Osteoporos. Int., 2005, 16, 713-716.

[29] Hanley, D.; Cranney, A.; Jones, G.; Whiting, S.; Leslie, W.; Cole, D.; Atkinson, S.; Josse, R.; Feldman, S.; Kline, G.; Rosen, C. Vitamin D in adult health and disease: a review and guideline statement from Osteoporosis Canada. CMAJ, 2010, 182, E610-E618.

[30] Souberbielle, J.C.; Body, J.J.; Lappe, J.; Plebani, M.; Schoenfeld, Y.; Wang, T.; Bischoff-Ferrari, H.; Cavalier, H.; Ebeling, P.; Fardellone, P.; Gandini, S.; Gruson, D.; Guerin, A.; Heickendorff, L.; Hollis, B.; Ish-Shalom, S.; Jean, G.; von Landenberg, P.; Largura, A.; Olsson, T.; Pierrot-Deseilligny, C.; Pilz, S.; Tincani, A.; Valcour, A.; Zittermann, A. Vitamin D and musculoskeletal health, cardiovascular disease, autoimmunity and cancer: recommendations for clinical practice. Autoimmunity Reviews, 2010, 9, 709-715.

[31] Priemel, M.; von Domarus, C.; Klatte, T.O.; Kessler, S.; Schlie, J.; Meier, S.; Proksch, N.; Pastor, F.; Netter, C.; Streichert, T.; Püschel, K.; Amling, M. Bone mineralization defects and vitamin D deficiency: histomorphometric analysis of iliac crest bone biopsies and circulating 25 -hydroxyvitamin D in 675 patients. $J$. Bone Miner. Res., 2010, 25, 305-312.

[32] Okazaki, R.; Sugimoto, T.; Kaji, H.; Fujii, Y.; Shiraki, M.; Inoue, D.; Endo, I.; Okano, T.; Hirota, T.; Kurahashi, I.; Matsumoto, T. Vitamin D insufficiency defined by serum 25-hydroxyvitamin D and parathyroid hormone before and after oral vitamin D3 supplementation load in Japanese patients. J. Bone Miner. Metab., 2011, 29, 103-110.

[33] Chapuy, M.C.; Preziosi, P.; Maamer, M.; Arnaud, S.; Galan, P.; Hercberg, S.; Meunier, P.J. Prevalence of vitamin D insufficiency in an adult normal population. Osteoporos. Int., 1997, 7, 439-443.

[34] Heaney, R.; Dowell, M,.; Hale, C.; Bendich, A. Calcium absorption varies within the reference range for serum 25-hydroxyvitamin D. J. Am. Coll. Nutr., 2003; 22: 142-146.

[35] Mithal, A.; Wahl, D.A.; Bonjour, J.P.; Burckardt, P.; DawsonHughes, B.; Eisman, J.; Fuleihan, G.E.H.; Josse, R.; Lips, P.; Morales-Torres, J. Global vitamin D status and determinants of hypovitaminosis D. Osteoporos. Int., 2009, 11,1807-1820.

[36] Hathcock, J.; Shao, A.; Vieth, R.; Heaney, R. Risk assessment for vitamin D. Am. J. Clin. Nutr., 2007, 85: 6-18.

[37] Tuohimaa, P.; Tenkanen, L.; Ahonen, M.; Lumme, S.; Jellum, E.; Hallmans, G.; Stattin, P.; Harvei, S.; Hakulinen, T.; Luostarinen, T.; Dillner, J.; Lehtinen, M.; Hakama, M.. Both high and low levels of blood vitamin D are associated with a higher prostate cancer risk: a longitudinal, nested case-control study in the Nordic countries. Int. J. Cancer, 2004,108,104-108.

[38] Stolzenberg-Solomon, R.Z.; Jacobs, E.J.; Arslan, A.A.; Qi, D.; Patel, A.V.; Helzlsouer, K.J.; Weinstein, S.J.; McCullough, M.L.; Purdue, M.P.; Shu, X.; Snyder, K.; Virtamo, J.; Wilkins, L.; Yu, K.; Zelenius-Jacquotte, A.; Zheng, W.; Albanes, D.; Cai, Q.; Harvey, C.; Hayes, R.; Clipp, S.; Horst, R.L.; Irish, L.; Koenig, K., Le Marchand, L.; Kolonel, L.N. Circulating 25-hydroxyviatmin D and risk of pancreatic cancer: cohort consortium vitamin $\mathrm{D}$ pooling project of rarer cancers. Am. J. Epidemiol., 2010, 172, 81-93.

[39] Luxwolda, M.; Kuiperst, R.; Kema, I.; Dijck-Brouwer, J.; Muskiet, F. Traditionnally living populations in East Africa have a mean serum 25-hydroxyvitamin D concentration of $115 \mathrm{nmol} / \mathrm{L}$. British Journal of Nutrition, 2012, Jan 23, 1-5 [Epub ahead of print]

[40] Hollis, B.W. The determination of circulating 25-hydroxyvitamin D: no easy task. J. Clin. Endocrinol. Metab., 2004, 89, 3149-3151.

[41] Lensmeyer, G.; Poquette, M.; Wiebe, D.; Binkley,N. The C3epimer of 25-hydroxyvitamin D3 is present in adult serum. J. Clin. Endocrinol. Metab., 2012, 97, 163-168.

[42] Elder, P.; Lewis, J.; King, R.; Florkowski, C. An anomalous result from gel tubes for vitamin D. Clinica Chimica Acta, 2009, 410, 95.

[43] Carter, G.; Jones, J.C.; Berry, J.L. The anomalous behaviour of exogenous 25 -hydroxyvitamin $\mathrm{D}$ in competitive binding assays. $J$. Steroid Biochem. Mol. Biol., 2007, 103, 480-482.

[44] Cavalier, E.; Wallace, M. ; Knox, S. ; Mistretta, V. ; Cormier, C. ; Souberbielle, J.C. Serum vitamin D measurement may not reflect what you give to your patients. J. Bone Miner. Res., 2008, 23, 1864-1865.

[45] Binkley, N.; Drezner, M.; Hollis, B.W. Laboratory reporting of 25hydroxyvitamin D results: potential for clinical misinterpretation. Clin. Chem., 2006, 52, 2124-2125.

[46] Hollis, B.W. Comparison of commercially available (125)I-based RIA methods for the determination of circulating 25-hydroxyvitamin D. Clin. Chem., 2000, 46, 1657-1661.

[47] Stepman, H.; Vanderroost, A.; Van Uytfanghe, K.; Thienpont, L. Candidate reference measurement procedures for serum 25OHD3 and 25OHD2 by using isotope dilution liquid chromatographytandem mass spectrometry. Clin. Chem., 2011, 57, 441-448.

[48] Heijboer, A.; Blankenstein, M.; Kema, I.; Buijs, M. Accuracy of 6 routine 25-hydroxyvitamin D assays; influence of vitamin D binding protein concentration. Clin. Chem., 2012, 58 in press.

[49] Farrell, C.J.; Martin, S.; McWhinney, B.; Straub, I.; Williams, P.; Hermann, M. State-of-the-art vitamin assays: a comparison of automated immunoassays with liquid chromatography-tandem mass spectrometry methods. Clin. Chem., 2012, 53 in press.

[50] Taieb, J.; Mathian, B.; Millot, F.; Patricot, M.C.; Mathieu, E.; Queyrel, N.; Lacroix, I.; Somma-Delpero, C.; Boudou, P. Testosterone measured by 10 immunoassays and by isotopedilution gas chromatography-mass spectrometry in sera from 116 men, women, and children. Clin. Chem., 2003, 49, 1381-1395.

[51] Boudou, P.; Taieb, J.; Mathian, B.; Badonnel, Y.; Lacroix, I.; Mathieu, E.; Millot, F.; Queyrel, N.; Somma-Delpero, C.; Patricot, M.C. Comparison of progesterone concentration determination by 12 non-isotopic immunoassays and gas chromatography/mass spectrometry in 99 human serum samples. J. Steroid Biochem. Mol. Biol., 2001, 78, 97-104.

[52] Barake, M.; Daher, R.; Salti I, Cortas N, Al-Saar L, Habib R, ElHajj-Fuleihan G. 25-hydroxyvitamin D assay variations and impact on clinical, decision making. J Clin Endocrinol metab, 2012; 97: 835-843.

[53] Binkley, N.; Krueger, D.; Cowgill, C.S.; Plum, L.; Lake, E.; Hansen, K.E.; DeLuca, H.; Drezner, M. Assay variation confounds the diagnosis of hypovitaminosis D: a call for standardization. $J$. Clin. Endocrinol. Metab., 2004, 89, 3152-3157.

[54] Hyppönen, E.; Turner, S.; Cumberland, P.; Power, C.; Gibb, I. Serum 25-hydroxyvitamin D measurement in a large population survey with statistical harmonization of assay variation to an international standard. J. Clin. Endocrinol. Metab., 2007, 92, 46154622.

[55] Cavalier, E.; Rozet, E.; Gadisseur, R.; Carlisi, A.; Monge, M.; Chapelle, J.P.; Hubert, P.; Souberbielle, J.C.; Delanaye, P. Measurement uncertainty of $25-\mathrm{OH}$ vitamin $\mathrm{D}$ determination with different commercially available kits: impact on the clinical cutoffs. Osteoporos. Int., 2010, 21, 1047-1051.

[56] Davidson, Z.; Walker, K.; Truby, H. Do glucocorticoids alter vitamin D status? A systematic review with meta-analyses of observational studies. J. Clin. Endocrinol. Metab., 2012, 97, 738-744.

[57] KDIGO. Clinical practice guideline for the diagnosis, evaluation, prevention, and treatment of chronic kidney disease-mineral and bone disorder (CKD-MBD). Kidney Int., 2009, 79, S1-S130.

[58] Kandula, P.; Dobre, M.; Schold, J.D.; Schreiber, M.; Mehrotra, R.; Navaneethan, S. Vitamin D supplementation in chronic kidney disease: a systematic review and meta-analysis of observational studies and randomized controlled trials. Clin. J. Am. Soc. Nephrol., 2011, 6, 50-62.

[59] Jean, G.; Souberbielle, J.C.; Chazot, C. Strategy for vitamin D supplementation. Monthly cholecalciferol administration in hemodialysis patients: a simple and efficient strategy for vitamin D supplementation. Nephrol. Dial. Transplant., 2009, 24, 3799-3805.

[60] Matias, P.J.; Jorge, C.; Ferreira, C.; Borges, C.; Aires, I.; Amaral, T.; Gil, C.; Cortez, J.; Ferreira, A. Cholecalciferol supplementation in hemodialysis patients: effects on mineral metabolism, inflammation, and cardiac dimensions parameters. Clin. J. Am. Soc. Nephrol., 2010, 5, 905-911.

[61] Courbebaisse, M.; Thervet, E.; Souberbielle, J.C.; Zuber, J.; Eladari, D.; Martinez, F.; Mamzer-Bruneel, M.F.; Urena, P.; Legendre, C.; Friedlander, G.; Prié, D. Effects of vitamin D supplementation on the calcium-phosphate balance in renal transplant patients. Kidney Int., 2009, 75, 646-651. 
[62] Pilz, S.; Iodice, S.; Zittermann, A.; Grant, W.; Gandini, S. Vitamin D status and mortality risk in CKD: a meta-analysis of prospective studies. Am. J. Kidney Dis., 2011, 58, 374-382.

[63] de Boer, I.H.; Katz, R.; Chonchol, M.; Sarnak, M.; Shlipak, M.; Siskovick, D.; Kestenbaum, B. Serum 25-hydroxyvitamin D and change in estimated glomerular filtration rate. Clin. J. Am. Soc. Nephrol., 2011, 6, 2141-2149.

[64] Kim, M.J.; Frankel, A.; Donaldson, M.; Darch, S.; Pusey, C.; Hill, P.; Mayr, M.; Tam, F. Oral cholecalciferol decreases albuminuria and urinary TGF- $\beta 1$ in patients with type 2 diabetic nephropathy on established renin-angiotensin -aldosterone system inhibition. Kidney Int., 2011, 80, 851-860.

[65] Grey, A.; Lucas, J.; Horne, A.; Gamble, G.; Davidson, J.; Reid, I. Vitamin D repletion in patients with primary hyperparathyroidism and coexistent vitamin D insufficiency. J. Clin. Endocrinol. Metab., 2005, 90, 2122-2126.

[66] Souberbielle, J.C.; Maury, E.; Friedlander, G.; Cormier, C. Vitamin $\mathrm{D}$ and primary hyperparathyroidism (PHPT). J. Steroid. Biochem. Mol. Biol., 2010, 121, 199-203.

[67] Eastell, R.; Arnold, A.; Brandi, M.L.; Brown, E.; D’Amour, P.; Hanley, D.; Rao, S.; Rubin, M.; Goltzman, D.; Silverberg, S.; Marx, S.; Peacock, M.; Mosekilde, L.; Bouillon, R.; Lewiecki, E. Diagnosis of asymptomatic primary hyperparathyroidism: proceedings of the third international workshop. J. Clin. Endocrinol. Metab., 2009, 94, 340-350.

[68] Lowe, H.; McMahon, D.J.; Rubin, M.; Bilezikian, J.; Silverberg, S. Normocalcemic primary hyperparathyroidism: further characterization of a new clinical phenotype. J. Clin. Endocrinol. Metab., 2007, 92, 3001-3005.

[69] Heaney, R.P. Vitamin D in health and disease. Clin. J. Am. Soc. Nephrol., 2008, 3, 1535-1541.

[70] Cashman, K.; Fitzgerald, A.; Kiely, M; Seamans, K. A systematic review and meta-regression analysis of the vitamin D intake-serum 25-hydroxyvitamin D relationship to inform European recommendations. Br. J. Nutr., 2011, 106, 1617-1627.

[71] Gallagher, J.C.; Sai, A.; Templin III, T.; Smith, L. Dose response to vitamin D supplementation in postmenopausal women. A randomized trial. Ann. Intern. Med., 2012, 156, 425-437.
[72] Toss, G.; Magnusson, P. Is a daily supplementation with 40 microgram vitamin D3 sufficient? A randomikzed trial. Eur. $J$. Nutr., 2011, [Epub ahead of print].

[73] Diamond, T.; Wong, Y.K.; Golombick, T. Effect of oral cholecalciferol 2,000 versus 5,000 IU on serum vitamin D, PTH, bone and muscle strength in patients with vitamin D deficiency. Osteoporos. Int., 2011, Epub ahead of print

[74] van Groningen, L.; Opdenoordt, S.; van Sorge, A.; Telting, D.; Giesen, A.; de Boer, H. Choecalciferol loading dose guideline for vitamin D deficient adults. Eur. J. Endocrinol., 2010, 162, 805-11.

[75] Holick, M.F. Vitamin D deficiency. N. Engl. J. Med., 2007, 357, 266-81.

[76] Ish-Shalom, S.; Segal, E.; Salganik, T.; Raz, B.; Bromberg, I.; Vieth, R. Comparison of daily, weekly, and monthly vitamin D3 in ethanol dosing protocols for two months in elderly hip fracture patients. J. Clin. Endocrinol. Metab., 2008, 93, 3430-3435.

[77] Sanders, K.M.; Stuart, A.L.; Williamson, E.J.; Simpson, J.; Kotowicz, M.; Young, D.; Nicholson, G. Annual high-dose oral vitamin $\mathrm{D}$ and falls and fractures in older women: a randomized controlled trial. J.A.M.A., 2010, 303, 1815-1822.

[78] Armas, L.A.G.; Hollis, B.W.; Heaney, R.P. Vitamin D2 is much less effective than vitamin D3 in humans. J. Clin. Endocrinol. Metab., 2004, 89, 5387-5391.

[79] Romagnoli, E.; Mascia, M.L.; Cipriani, C.; Fassino, V.; Mazzei, F.; D'Erasmo, E.; Carnevale, V.; Scillitani, A.; Minisola, S. Short and long term variations in serum calciotropic hormones after a single very large dose of ergocalciferol (vitamin D2) or cholecalciferol (vitamine D3) in the elderly. J. Clin. Endocrinol. Metab., 2008, 93, 3015-3020.

[80] Holick, M.; Biancuzzo, R.M.; Chen, T.C.; Klein, E.; Young, A.; Bibuld, D.; Reitz, R.; Salameh, W.; Ameri, A.; Tannenbaum, A. Vitamin D2 is as effective as vitamin D3 in maintaining circulating concentrations of 25-hydroxyvitamin D. J. Clin. Endocrino.l Metab., 2008, 93, 677-681.

[81] Heaney, R.; Recker, R.; Grote, J.; Horst, R.; Armas, L. Vitamin D3 is more potent than vitamin D2 in humans. J. Clin. Endocrinol. Metab., 2011, 96, E447-E452. 